University of Wollongong

Research Online

Faculty of Commerce - Papers (Archive)

Faculty of Business and Law

January 2005

\title{
Evaluating the Quality of Health Web Sites: Developing a Validation Method and Rating Instrument
}

D. Bomba

University of Wollongong, bomba@uow.edu.au

Follow this and additional works at: https://ro.uow.edu.au/commpapers

Part of the Business Commons, and the Social and Behavioral Sciences Commons

\section{Recommended Citation}

Bomba, D.: Evaluating the Quality of Health Web Sites: Developing a Validation Method and Rating Instrument 2005.

https://ro.uow.edu.au/commpapers/1

Research Online is the open access institutional repository for the University of Wollongong. For further information contact the UOW Library: research-pubs@uow.edu.au 


\title{
Evaluating the Quality of Health Web Sites: Developing a Validation Method and Rating Instrument
}

\author{
Abstract \\ Within the field of consumer health informatics there is a need to develop transparent validation methods \\ and rating instruments both of sufficient complexity and reliability to help designers, evaluators and \\ patients to evaluate the quality of health web sites and health information on the Web. Further refinement \\ and validation of the Bomba and Land Consumer Health Website Rating Index (v.1) was conducted. This \\ paper reports on the validation approach utilised (a combination of the Delphi Technique and Sullivan's 5 \\ step process) to produce version 2 of the Bomba and Land Index.

\section{Disciplines} \\ Business | Social and Behavioral Sciences

\section{Publication Details} \\ This paper originally appeared as: Bomba, D, Evaluating the Quality of Health Web Sites: Developing a \\ Validation Method and Rating Instrument, Proceedings of the 38th Annual Hawaii System Sciences, 3-6 \\ January 2005, 139-148. Copyright IEEE 2005.
}




\title{
Evaluating the Quality of Health Web Sites: Developing a Validation Method and Rating Instrument
}

\author{
David Bomba \\ Centre for Health Service Development and the School of Information Technology and Computer Science, University \\ of Wollongong, New South Wales, Australia \\ david_bomba@uow.edu.au
}

\begin{abstract}
Within the field of consumer health informatics there is a need to develop transparent validation methods and rating instruments both of sufficient complexity and reliability to help designers, evaluators and patients to evaluate the quality of health web sites and health information on the Web. Further refinement and validation of the Bomba and Land Consumer Health Website Rating Index (v.1) was conducted. This paper reports on the validation approach utilised (a combination of the Delphi Technique and Sullivan's 5 step process) to produce version 2 of the Bomba and Land Index.
\end{abstract}

\section{Introduction}

As an emerging discipline, Consumer Health Informatics (CHI) is "the branch of medical informatics that analyses consumers' needs for information; studies and implements methods of making information accessible to consumers; and models and integrates consumers' preferences into medical information systems" [1]. The pressing issues currently facing CHI researchers are (i) how can these concepts be operationalised into helpful instruments/artefacts for website/system designers and patients; and (ii) how should they be validated?

As life expectancy rates and expectations increase, patients are becoming more resourceful and demanding of health care providers. There has been an increased effort towards involving patients in choices about their health care through greater utilisation of computer technology both for health service delivery as well as health information delivery $[2,3]$. Some patients want to become more responsible for managing their own health care and to become active rather than passive recipients $[4,5]$. Information access has the potential to transform and democratise the paternalistic power relationship between consumer and health professional [6]. The movement to transform these power relations is reflective of a push towards developing a more intelligent web, otherwise known as the semantic web, a fusion of data and intelligent agents.

Consumer health information websites and portals are innovative methods of making health information, medical records and decision-support systems more accessible to consumers over the World Wide Web [7, 8]. Examples of portals include: www.healthinsite.gov.au and www.healthfinder.gov. The emergence of these websites/portals assumes that patients want to have greater involvement in health care choices and decisions. However, such innovations are not without problems, including level of usage; barriers to access; and lack of regulation and evaluation. While some authors argue that increasing numbers of consumers are turning to the Internet for health related information [9], Eysenbach argues [10] that empirical data on the actual frequency of health-related searches on the web are missing and that health related searches may constitute less than $5 \%$ of all searches. A survey conducted in March 2003 by the Center for Studying Health System Change found that $16 \%$ of adult Americans seek health information online [11]. However, it is still unclear what consumers do with the information and whether it has any correlation to changes in learning, behaviour and health outcomes.

There are also significant barriers to access, for example, computing skills, access to the technology, differing levels of health literacy and socio-economic wealth (this is often described as the digital divide, information rich/poor). In addition, the lack of regulation and evaluation of health information on the Internet and WWW continues to be a major problem $[12,13,14,15]$. This led the Australian National Electronic Decision Support Taskforce to comment that "... because of the quantity of information, clinicians and consumers are faced with the difficulty of sorting the wheat from the chaff." [16]. Information production and distribution has outstripped human ability to process it all, in some cases leading to information overload, mis-information and worse [17].

A number of innovations have been proposed to help assess the quality of health information on the WWW: codes of conduct, third-party certification/quality assurance marking, logos, quality seals, specially 
designed search engines, evaluation instruments, quality labels, user guides and filters $[18,19,20]$. An example of an online tool is www.discern.org.uk, a standardised index to assess the quality of health information. There are also international attempts to create filtering and rating systems (e.g www.medcertain.org) and systems for evaluating the web for accessibility. Zeng and Parmanto constructed a framework for the measurement of Web Accessibility Barriers (WAB). Results showed that the websites rate very poorly in being accessible to people with disabilities [21].

Eysenbach et al., examined 79 empirical studies that assessed the quality of health information for consumers on the WWW. They identified 86 different quality criteria of which the most frequently used were: accuracy, completeness, readability, design, disclosures and references provided. Fifty-five studies $(70 \%)$ concluded that quality is a problem on the Web, $17(22 \%)$ were neutral, and 7 studies $(9 \%)$ were positive about the quality of the sites reviewed. The authors concluded that there is a large amount of quality variation between web sites and the quality of medical information on the web. They argued that differences in study methods and rigor, quality criteria, study population, and topic chosen led to large variations in outcomes, and that operational definitions of quality criteria are needed [20].

Jadad and Gagliardi also question the validity of instruments used to assess the quality of websites [22]. Only 5 of the instruments they considered provided some information by which they could be evaluated. Huang highlights similar problems associated with assessing the quality of health rating instruments [23]. Both studies show that rating instruments are incomplete and provide very little information about how they are constructed and validated $[22,23]$. "There is growing understanding that all measuring instruments must be critically and empirically examined for their reliability and validity." [24].

The Bomba and Land Consumer Health Rating Index (v.1) was developed specifically to evaluate websites targeted at health consumers [25]. Based on the work of Slack [4] and the HONcode principles [26], it uses a series of guidelines with multiple sub-items to score individual sites. Sullivan's 5 step process in developing a multiple item index was adopted in order to ensure internal validity of the instrument [27]. In this way, the Index incorporates a validation technique to assess the evaluation instrument itself. This paper reports on efforts to incrementally revise the Index to include the views and perspectives of public health experts.

\section{Background}

The Bomba and Land Index (v.1) was developed using Sullivan's five steps, namely: (i) developing many potential items; (ii) elimination of items that are redundant or inappropriate for measuring the variable; (iii) pre-testing the remaining items for validity and reliability; (iv) eliminating items that do not pass the tests of step (iii); and (v) repeating steps (iii) and (iv) as often as necessary to refine the index.

After reviewing a summary of rating instruments [22], as well as consulting general literature on information systems and web design, a combined health specific evaluation framework based on the work of Slack [4] and the HONcode was developed [26].

Slack provides 9 guidelines for evaluation (1) medical soundness; (2) ease of use; (3) interactivity; (4) user benefits; (5) the patient in charge; (6) confidentiality; (7) availability; (8) reliability; and (9) subject to formal study with volunteers in an experimental setting, before being offered to the public [4]. The word "program" as originally used by Slack can refer to standalone software but has been expanded to include the WWW for the purposes of this study.

The 8 HONcode Principles are: (1) authority; (2) complementary; (3) confidentiality; (4) attribution; (5) justifiability; (6) transparency of authorship; (7) transparency of sponsorship; and (8) honesty in advertising and editorial policy [26]. It should be noted that the HONcodes are not specifically a rating system but are aimed at raising the quality of healthcare information on the Web by targeting both developers (in terms of presentation design standards) and readers (in terms of source reliability). As such, it is a self-regulatory and voluntary certification system.

Slack and HONcode have two guidelines in common, Slack's "medically sound" equates to the HONcode principle of "authority" meaning that those who provide medical advice should be suitably qualified. The second common guideline in both frameworks is "confidentiality" meaning that users information is protected if patient data is collected. By combining the two frameworks (and only counting the reoccurring guidelines once) a comprehensive index was produced. This was then tested against a selection of 30 Australian health portals to see if the wording of the guidelines needed to be reviewed. Some of the guidelines in the index were then re-worded to better suit the WWW environment.

In order to validate the instrument it was submitted to a pre-test with users. A convenience sample of university students (final year undergraduates and Masters students) studying consumer health informatics at the University of Wollongong, Australia, was constructed. In addition to being heavy users of the web, the sample group were knowledgeable about web and health website design. The key objectives in the instrument pre-testing process with users were: (i) to identify if there were any important guidelines missing; (ii) to get users to provide operationalised definitions for guidelines; (iii) to rank the guidelines in order of importance; and (iv) to test the 
instrument they had constructed against the Health Insite portal (www.healthinsite.gov.au).

Five by two hour focus groups were conducted in computer labs with 15-20 users per focus group $(n=85)$. A worksheet containing the 15 guidelines (but no definitions) was distributed to each user. Users were then given 30 minutes to identify any missing guidelines and write down their definitions. They were also asked to rank the guidelines in order of priority from 1 to 15 ( 1 being most important). Users then tested their instruments on Health Insite.

After pre-testing was completed, an open discussion on the guidelines, definitions and rankings ensued. The purpose of the discussion was to determine if any key guidelines had been missed and to give users an opportunity to revise their definitions based on the discussion. The researchers used this data to produce a comprehensive list of operationalised sub-items for each guideline. Each individual participant's ranking was used to produce a final ranked order of guidelines.

A further round of focus groups, repeating Sullivan's steps (iii) and (iv), were held using the revised index with the same cohort several weeks later. The second round of testing was conducted to verify and validate the range of operationalised items. Users were asked to add any further definitions/modifications to the range provided or to delete any they thought did not apply.

\section{Materials and Method}

In developing the Bomba and Land Index (v.1), one of the suggestions for further refinement was to incorporate a range of other views and perspectives in the validation process. The original index was developed using health informatics students as evaluators. To strengthen the evaluation method, the Delphi Technique was used in conjunction with Sullivan's 5 step approach to create a multiple item index to develop a consensus judgement amongst public health experts [28]. Following the recommendations of previously published work, the approach in this research seeks to further develop a transparent framework for others to follow or modify [25]. While the validation method was developed specifically to evaluate the Bomba and Land Index, it could also be used by other researchers to critically assess the content validity of other types of measuring instruments.

\subsection{The Delphi Technique}

To strengthen the internal validation technique, a multi-method research framework utilizing Sullivan's 5 steps and the Delphi Technique was created. The Delphi Technique is a process for gathering opinions from experts [29]. It is a useful decision-making approach which utilises anonymity and iterative feedback (see
Figure 1 below). Accordingly, "the Delphi method provides an opportunity for experts (panelists) to communicate their opinions and knowledge anonymously about a complex problem, to see how their evaluation of the issue aligns with others, and to change their opinions, if desired, after reconsideration of the findings of the group's work. The work continues over a series of iterative rounds until consensus or stability is reached about the problem at hand" [30]. The Public Health Informatics Research Laboratory at the University of Maryland, USA, used the Internet to facilitate and expediate the Delphi Process using online technology. This prompted the idea of incorporating the use of email and the Delphi Technique into the validation method for the Bomba and Land Index.

It needs to be noted that the strengths of the Delphi method has also been seen as a limitation "... the anonymity and release from peer pressure could be considered to lead to a lack of responsibility and accountability for responses ... yet lack of peer pressure removes certain social constraints that could affect the outcomes if all of the experts were face-to-face, with the more dominant, or powerful, voices gaining more weight. Defining experts can also be problematic and arbitrary ..." [30].

In the case of this research, it was felt that the combination of the Delphi Technique and Sullivan's 5 steps would overcome any limitations inherent in either approach. The Delphi Technique was used at Step 3 of Sullivan's schemata (see below). It involved health experts, acting as judges, independently reviewing the index.

\section{Step 1: (Re)-Developing potential items}

It needs to be acknowledged that the development of evaluation criteria/sub-items has been an evolving process, accountability criteria such as disclosure of authorship, ownership and currency of information, have been proposed as measures of quality of web based health information [31]. However, indicators or measures of quality are subjective and contested (e.g. accountability/presentation indicators vs. content indicators). The content covered in the Bomba and Land Index was re-compared with other health rating instruments and reviews [19, 20, 32] as well as general literature on information systems and web design. This included the following items identified by Anderson and Goodman [33]:

- HONcode principles (for publishers of health information)

- $\quad$ eHealth code of Ethics

- TRUSTe's Consumer Privacy Protection Guidelines and Model Privacy Statement

- Ethical Principles for Offering Internet Health Services to Consumers 
- Criteria for Assessing the Quality of Health Information on the Internet

- Information quality tools

- Principles Governing AMA Publications Web Sites

Modifications to terminology were incorporated to better operationalise some sub-items.

\section{Step 2: Elimination of items}

The Index was then tested on three selected Australian palliative care websites. As an initial sampling schema sites were selected to represent government (.gov), nongovernment (.org) and private ownership (.com). After careful examination of the index, it became evident that some questions could be simplified further and also some redundancy and overlap could be eliminated.

\section{Step 3: Pre-testing}

At Step 3, the Delphi Technique was utilised to revalidate the instrument by submitting it to a pre-test with 3 appropriate public health experts at the Centre for Health Service Development, University of Wollongong.

The key objectives in the instrument pre-testing process with health experts was: (i) to identify if there were any important guidelines missing; (ii) to get health experts to verify operationalised definitions for the guidelines; (iii) to rank the guidelines in order of importance; and (iv) to assign relative weightings. In this study, the guidelines were re-arranged on the worksheet so that the most important guidelines in the original Bomba and Land Index did not appear first but last and vice versa to see if this had an impact on ranking.

Two possible approaches were considered:

(i) an initial two hour focus group could be run by a moderator to be conducted with a convenience sample of public health experts. A worksheet containing the Bomba and Land Index would be distributed to each health expert and instructions provided. Participants would then be given 40 minutes to identify any missing guidelines and verify the operationalised definitions. They would also be asked to rank the guidelines in order of priority from 1 to 15 ( 1 being most important) and to provide a relative weighting.

(ii) a moderator would email a convenience sample of 3 public health experts. Instructions would be provided with the Bomba and Land Index worksheet which would be attached for them to review. They would be given a week to conduct the review and to return their worksheet and comments via email to the moderator.

It was decided to use approach (ii) as this would allow greater time for reflection and completion of the task. Also, peer pressure dynamics to conform due to group interaction could be minimised and independence and anonymity maintained.

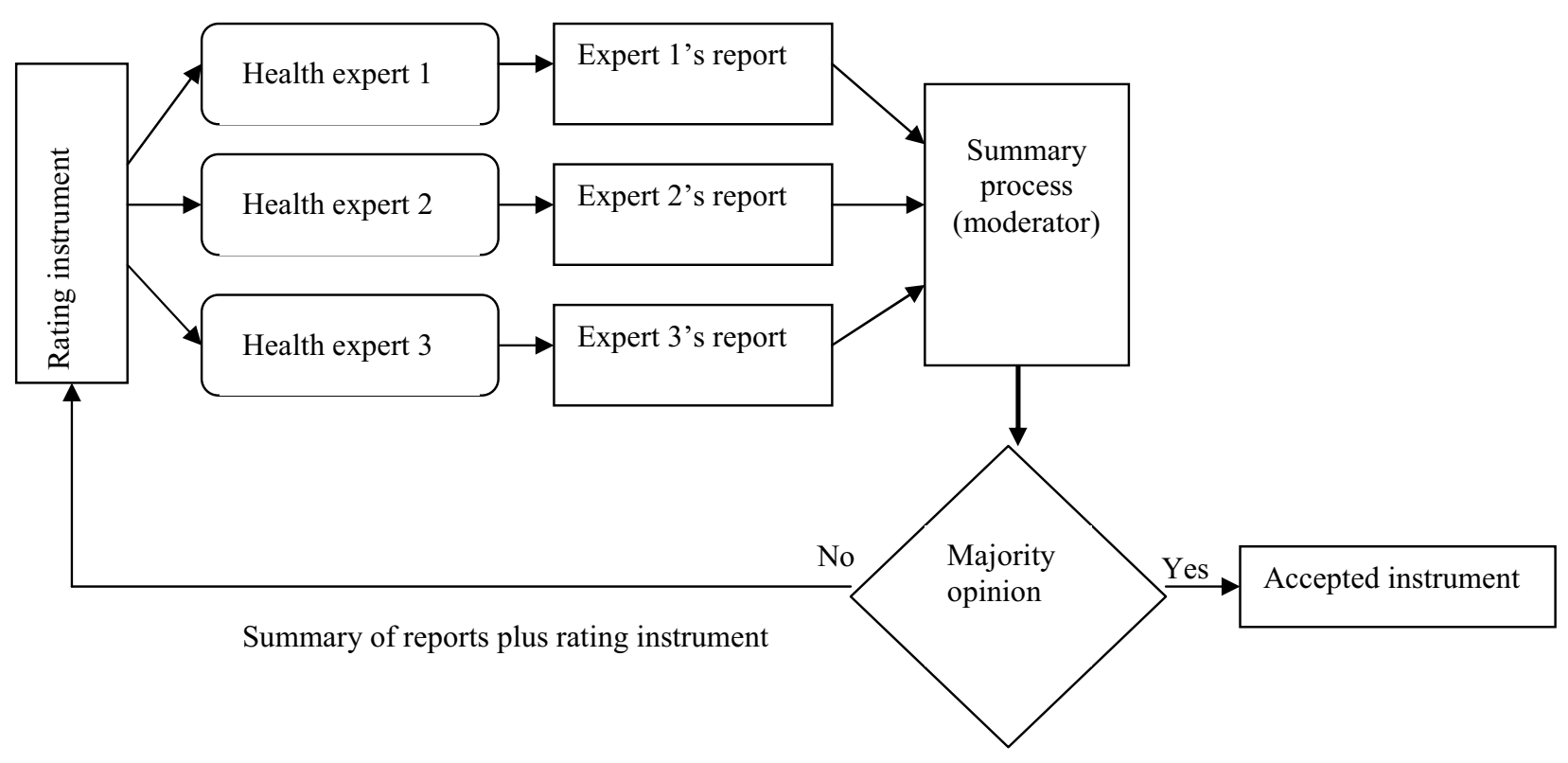

Figure 1. Adapted Delphi Method (source: Friedman and Wyatt [28]) 


\section{Step 4: Eliminating items that do not pass the test}

After pre-testing of the worksheet was completed, experts were also asked to provide their comments on the guidelines, definitions, rankings and weightings. The moderator used this data to produce a new version of the Index.

\section{Step 5: Refinement}

A second round of email discussion was undertaken, repeating Sullivan's steps (iii) and (iv), using the revised index with the same cohort several weeks later. The second round of testing was conducted to verify and validate the range of operationalised items. Users were asked to refine/modify the range of sub-items provided.

A final version of the Bomba and Land Index (v.2) was devised (see Table 1, Appendix). This was then recirculated back to the participants via email for final consensus and checking.

\section{Results and Discussion}

Following expert feedback, some further redundancy was identified and some guidelines were converged into single thematic guidelines. The guidelines which were considered by the experts for possible merging were: (i) advertising and editorial policy with transparency of authorship, (ii) attribution with authorship, immediate benefit to user with easy to use and with patient/user in charge (iii) subject to formal study with attribution (and authorship) with medically sound. The wording of some sub-items were further refined and improved. Also, double-barrelled questions were identified which needed to be broken down. Furthermore, some guidelines and sub-items were only identified as being optional since they may not apply to all sites. For example, if a site does not require the user to input any personal information, the guideline "Confidentiality" should be optional. This raised the issue of whether a non-applicable code was needed. On further discussion it was decided that there may be a tendency to use non-applicable instead of "no" and this could distort the scoring.

Another issue raised was whether the guidelines should be weighted. The issue of ranking guidelines was a highly subjective and difficult process. The first 3 rankings seemed to be relatively consistent but the rest were difficult to rank. There was even discussion of whether the operationalised sub-items should also be ranked and weighted within guidelines. The number of items within a guideline was also raised as an issue and whether there should be equal amounts of items across the guidelines. The consensus at the end of the process was that some guidelines were deemed to be more important and that this was also reflected by the number of items being assessed and therefore a ranking and weighted multiplier was agreed upon.

The complete instrument can be used by designers, evaluators and patients to evaluate a health website. Each guideline is operationalised with a range of sub-items, each with a possible value of 1 (yes) or 0 (no) (see Table 1 ). The guidelines are also weighted, with the highest ranked guideline having a rank multiplier value 6 times more than the last guideline (see Table 1). The total weighted value for each guideline is calculated by multiplying the value of the sub-item divided by the total number of sub-items multiplied by the rank multiplier. For example, each sub-item answered "yes" for the guideline "complimentary and interactive" (ranked 5) has a value of $2 *(1 / 7)$. The total score is a summation of the scores for each guideline.

The challenge of this work is to produce an effective index without it becoming a lengthy and unwieldy instrument. The Bomba and Land Index (v.2) compares well to the quality criteria groups as stated by Kim [32], Jadad and Gagliardi [14], and Eysenbach [20]. The index tries to capture items that cover both website design and functionality as well as the quality of content. The expert panel raised the idea of developing a long and a short version of the Index, along similar lines to the SF-12 and SF-36 used in Mental Health [34]. The experts were concerned about the lengthy nature of the original index and how this may impact on usability. The longer it takes to complete the evaluation the less likely consumers are to use it. Consumers would probably not stand for spending over 30 minutes conducting an evaluation of a single site. Due to the growing complexity of the rating system it may well be that a third party evaluator conducts the actual rating rather than the consumer. Evaluator independence may need to be considered further. Developing a web-based online version could also reduce the length of time needed to compile the final score. All the calculations would be performed behind the scenes within the program logic and all that would be needed is for the consumer to tick a box next to the various subitems, similar to a check-list and a summary score produced.

Another challenge was trying to produce an instrument that analyses website design quality and information content from the designers perspective (design criteria for a good website) as well as from the consumers perspective (how reliable is the health information on the site). This raised a number of important but related subissues: (i) ratings may differ based on the primary motivation of the seeker - are they looking for detailed clinical information, service provider information, general (non-clinical) support information?; (ii) some items are dependent on the user's access to technology (i.e. userspecific rather than site-specific issues, for example, does the user have broadband access versus dial-up, loading of graphics, type of browser etc). 
The process followed has resulted in a more refined and validated version 2 of the Bomba and Land Index. However, it is acknowledged that only having 3 public health experts as part of the Delphi Technique can be seen as a methodological limitation and a larger sample of public health experts would be more desirable in future studies. Also, selection criteria for defining an expert may need to be considered more carefully (e.g qualifications, seniority, years of practice etc). Of the 3 experts in this study, one had over 20 years experience working in the public health sector, one had over 10 years experience working in the field of health informatics, and the third was a practising IT health specialist with over 8 years experience.

The way forward for this research is twofold: (i) to continue to review and develop an all inclusive list of criteria and sub-items (Step 1 of Sullivan's process); (ii) test the index on a range of websites and to further develop a rating scale. This work is currently underway.

In order to realise the possible benefits of a quality rating instrument it needs to gain wider adoption and recognition not only by users but by professional peers in consumer health informatics. For consumers, it needs to be easy to use and for professional peers it also has to be methodologically sound. The index can help consumers to become more active participants in their health care decision making by being more questioning and critical about health information on the Web. However, the final decision to act on information or a rating still lies with the consumer.

\section{Conclusions}

The consumer health informatics mission can be redefined as developing decision support systems for patients to be able to make reasonably informed choices about their health care. However, patient motivations for seeking information will vary as will interpretation of health information and therefore outcomes. This is dependent to a certain extent on an individual's health literacy and education level. Consumers are in need of more useful ways of being able to assess the quality of websites. Third party intermediaries such as evaluators can be seen to act as proxies for the public in helping to set a best practice standard for designers and content providers to adhere to. Whether they actually do voluntarily, however, is another issue. Establishing evaluator independence is an important associated factor. However, determining the actual level of independence (at an arm's distance) may be more difficult since evaluators do not operate in a political vacuum but are themselves part of wider networks of associations and dependencies.

Assessing quality will always be a subjective process and people, even experts, assess quality differently. There may well be a difference between the views of consumer users about the quality of health information on a website and the views of experts. A site may be visually appealing and easy to use and read but medically unsound. Therefore, the development of an index and what items to include or exclude will always be an inherently political process. Debates about the transparency of instrument construction and validation are important and have more general applicability beyond just being discussed by research methodologists in consumer health informatics.

The aim of the next stage of this research is to design an online instrument that consumers can use to evaluate websites. A web based version is currently being developed. This will also be a useful exercise in improving the visual design and layout of the instrument. Another initiative is to have a validation and development website available without charge on the Internet to developers which could contain a frequently asked questions section and discussion board. This is also currently being devised. This would help in making more explicit discussions about devising better algorithms for calculating rating results. Results could also be pooled and published on the site by other researchers. This type of website initiative is important since both instruments and operationalised definitions will need to change over time to reflect new developments in health and technology. New guidelines and items may need to be added in the future.

Although moving towards the adoption of a standardised rating instrument is appealing, the Bomba and Land Index (v.2) is not a gold standard. Claims of having developed a superior quality rating instrument can be professionally hazardous. Developing a comprehensive index that all consumer health informatics experts can agree on is a complex and longitudinal process. This research is one small step in helping to fill a knowledge gap identified by other researchers, namely making the process of instrument construction and validation more transparent. Finally, once the process of validation becomes more transparent, there will be an associated need to try and measure the actual impact and correlation between good quality health information and patient health outcomes.

\section{References}

[1] G. Eysenbach, "Recent Advances: Consumer Health Informatics," British Medical Journal, vol.320, pp.1713-6, 2000.

[2] A. Edwards, and G. Elwyn, Evidence-based patient choice, Oxford: Oxford University Press, 2001.

[3] G. Eysenbach, and A. Jadad, "Consumer health informatics in the internet age," in Evidence-based patient choice, Edwards A, Elwyn G, Eds. Oxford: Oxford University Press, 2001. 
[4] W. Slack, Cybermedicine: How Computing Empowers Doctors and Patients for Better Health Care, San Francisco: Josey-Bass Publishers, 2001.

[5] D. Bomba, and T. Land, "A Survey of Patient Attitudes Towards the Use of Computerised Medical Records and Unique Identifiers in Four Australian GP Practices," The Journal on Information Technology in Healthcare, vol.1(1), pp.31-45, 2003.

[6] E. Coiera, "Digital doctors - will the Internet replace your doctor?" ABC Radio Health Report, 1999.

[7] D. H. Gustafson, R. Hawkins, and E. Boberg, "Impact of a patient centered, computer-based health information/support system," American Journal of Preventative Medicine, vol.16(1), pp.1-9, 1999.

[8] D. H. Gustafson, F. McTavish, and R. Hawkins, "Computer support for elderly women with breast cancer," Journal of the American Medical Association, vol.280(15), pp.1305, 1998.

[9] D. Lindberg, and B. Humphreys, "Medicine and Health on the Internet: The Good, the Bad, and the Ugly," Journal of the American Medical Association, vol.280, pp.1301-1304, 1998.

[10] G. Eysenbach, "What is the Prevalence of Health-related Searches on the World Wide Web?," presented at American Medical Informatics Association Conference, 2003.

[11] T. Chin, "New survey finds fewer patients searching online," American Medical News, vol.46(14), pp.17, 2003.

[12] M. Rigby, J. Forsstrom, R. Roberts, and J. Wyatt, "Verifying Quality and Safety in Health Informatics Services," British Medical Journal, vol.323, pp.552-556, 2001.

[13] G. Eysenbach, and C. Kohler, "How Do Consumers Search for and Appraise Health Information on the World Wide Web? Qualitative Study Using Focus Groups, Usability Tests, and in-depth Interviews," British Medical Journal, vol.324, pp.573-577, 2002.

[14] A. R. Jadad, and A. Gagliardi, "Rating health information on the Internet: navigating to knowledge or to Babel?," Journal of the American Medical Association, vol.279(8), pp.611-4, 1998.

[15] A. Risk, and C. Peterson, "Health Information on the Internet: Quality Issues and International Initiatives," Journal of the American Medical Association, vol.287, pp.2713$2715,2002$.

[16] National Electronic Decision Support Taskforce, Electronic Decision Support, Canberra: Commonwealth of Australia, 2002.

[17] L. Theodosiou, and J. Green, "Emerging challenges in using health information from the internet," Advances in Psychiatric Treatment, vol.9, pp.387-396, 2003.

[18] P. Wilson, "How to find the good and avoid the bad or ugly: a short guide to tools for rating quality of health information on the Internet," British Medical Journal, vol.324, pp.598-602, 2002.

[19] A. Risk, and J. Dzenowagis, "Review of Internet Health Information Quality Initiatives," Journal of Medical Internet Research, vol.3(4), pp.e28, 2001.

[20] G. Eysenbach, J. Powell, O. Kuss, and E. Sa, "Empirical Studies Assessing the Quality of Health Information for Consumers on the World Wide Web," Journal of the American Medical Association, vol.287(20), pp.2691-2700, 2002.
[21] X. Zeng, and B. Parmanto, "Evaluation of Web Accessibility of Consumer Health Information Websites," presented at American Medical Informatics Association Conference, 2003.

[22] A. R. Jadad, and A. Gagliardi, "Examination of instruments used to rate quality of health information on the internet," British Medical Journal, vol.324, pp.569-573, 2002.

[23] Q. R. Huang, "Creating informed consumers and achieving shared decision making," Australian Family Physician, vol.32, pp.335-340, 2003.

[24] F. Kerlinger, Foundations of Behavioral Research, New York: Holy, Rinehart and Winston, 1986.

[25] D. Bomba, and T. Land, "Constructing and Validating a Consumer Health Portal Rating Index," presented at The World Medical Informatics Conference 2004, San Francisco, 2004.

[26] Health On the Net Foundation, "HON Code of Conduct (HONcode) for medical and health Web sites", Web-site: http://www.hon.ch/HONcode/Conduct.html, Accessed: 12 June 2004

[27] T. S. Sullivan, Methods of Social Research: Harcourt College Publishers, 2001.

[28] C. Friedman, and J. Wyatt, Evaluation Methods in Medical Informatics, New York: Springer, 1997.

[29] M. Q. Patton, Utilization-focused evaluation, Newbury Park, CA: Sage Publications, 1986.

[30] H. Kennedy, "Enhancing Delphi research: methods and results," Journal of Advanced Nursing, vol.45(5), pp.504$511,2004$.

[31] W. Silberg, G. Lundberg, and R. Musacchio, "Assessing, controlling and assuring the quality of medical information on the internet," Journal of the American Medical Association, vol.277, pp.1244-5, 1997.

[32] P. Kim, T. Eng, J. Deering, and A. Maxfield, "Published criteria for evaluating health related web sites: review," British Medical Journal, vol.318, pp.647-649, 1999.

[33] J. Anderson, and K. Goodman, Ethics and Information Technology: A Case Based Approach to a Health Care System in Transition, New York: Springer-Verlag, 2002.

[34] J. Ware, M. Kosinski, and S. Keller, SF-36 Health Survey: Manual and Interpretation Guide, Lincoln, RI: QualityMetric Incorporated, 2003. 
Table 1. Health website and health information rating index (version 2)

\begin{tabular}{|c|c|c|c|}
\hline Guidelines & Ranking & Operationalised sub-items & $\begin{array}{l}\text { Weighted } \\
\text { Multiplier }\end{array}$ \\
\hline $\begin{array}{l}\text { Content is } \\
\text { medically sound, } \\
\text { justifiable, clearly } \\
\text { attributed, and } \\
\text { subject to formal } \\
\text { study }\end{array}$ & 1 & $\begin{array}{l}\text { 1. Are the (medical) credentials/qualifications of the content } \\
\text { providers and developers visible? } \\
\text { 2. Is the organisation or content provider recognisable to the user } \\
\text { (e.g. AMA, or a major national academic or professional } \\
\text { institution)? } \\
\text { 3. Is there a disclaimer notice on the homepage? } \\
\text { 4. Is there a statement about how information is evaluated (eg. is } \\
\text { there an approval process) or is someone named as responsible } \\
\text { for overview of all content? } \\
\text { 5. Is the origin of the information stated (e.g. fact or opinion, } \\
\text { primary or secondary documents)? } \\
\text { 6. Is there a balanced presentation of any evidence relating to } \\
\text { treatments, products or services (i.e. advantages and } \\
\text { disadvantages/side-effects)?* } \\
\text { 7. Does each topic or article have cross-referencing links to other } \\
\text { published research results and further supporting articles?* } \\
\text { 8. Does the site indicate how it is judged and accredited? } \\
\text { 9. Is the site fully open to public scrutiny and evaluation (i.e. no } \\
\text { registration, logins, passwords or closed sections requiring fees } \\
\text { to access additional features and information)? } \\
\text { 10. Are the content partners for this site visible/declared (i.e. when } \\
\text { clicking on a link that takes you to another site or information } \\
\text { on the site itself)? }\end{array}$ & 6 \\
\hline $\begin{array}{l}\text { Easy to use and } \\
\text { immediate benefit } \\
\text { to the user }\end{array}$ & 2 & $\begin{array}{l}\text { 1. Is the language used understandable (i.e. medical terms } \\
\text { simplified to layman's terms) and if not is there a glossary? } \\
\text { 2. Does the site use a classification system or categorise } \\
\text { information into topics/subject headings? } \\
\text { 3. Is there a static frame with key links displayed (e.g. a consistent } \\
\text { left, top or bottom bar providing links throughout the site)? } \\
\text { 4. Are the site buttons clear and visible? } \\
\text { 5. Is a sitemap link available? } \\
\text { 6. Is there a site search function available? } \\
\text { 7. Can the user always find the link to the home page? } \\
\text { 8. Can the user personalise the website presentation style (e.g. } \\
\text { language options)? } \\
\text { 9. Can the user navigate through the site without problems? } \\
\text { 10. Is the intended audience described or is the purpose of the } \\
\text { website stated? } \\
\text { 11. Is information provided on when the site was created or } \\
\text { updated? } \\
\text { 12. Is there a Frequently Asked Questions (FAQs) section? } \\
\text { 13. Can the user get on-line help from the site (e.g email the } \\
\text { webmaster)? }\end{array}$ & 5 \\
\hline $\begin{array}{l}\text { Fast, reliable and } \\
\text { readily available }\end{array}$ & 3 & $\begin{array}{l}\text { 1. Was the URL accessible? } \\
\text { 2. Did it take less than } 8 \text { seconds to download the homepage? } \\
\text { 3. Did the website load correctly? } \\
\text { 4. Is each page useable (i.e. no broken links, images load, no pop- } \\
\text { ups)? } \\
\text { Can the site be viewed with another browser (e.g Explorer and } \\
\text { Navigator)? }\end{array}$ & 4 \\
\hline
\end{tabular}




\begin{tabular}{|c|c|c|c|}
\hline $\begin{array}{l}\text { Advertising and } \\
\text { editorial policy } \\
\text { and transparency } \\
\text { of authorship and } \\
\text { sponsorship }\end{array}$ & 4 & $\begin{array}{l}\text { 1. Is there a visible policy statement about advertising (e.g. } \\
\text { banners, logos, products) on the site? } \\
\text { 2. If there is advertising, is the advertising material separate from } \\
\text { research/medical content material?* } \\
\text { 3. Is there information about who is on the editorial board and } \\
\text { their contact details or are the contact details (e.g. email, } \\
\text { address, phone number) for the site owners/webmaster/designer } \\
\text { displayed? } \\
\text { 4. Does the site declare/list any support from private companies or } \\
\text { public/government organisations? } \\
\text { 5. Do the site owners declare any financial interest in the content } \\
\text { (i.e. do they declare any financial interest they derive from the } \\
\text { content or running of the site)? }\end{array}$ & 3 \\
\hline $\begin{array}{l}\text { Complimentary } \\
\text { and interactive }\end{array}$ & 5 & $\begin{array}{l}\text { 1. Are patients encouraged to contact a health professional if they } \\
\text { are concerned about a health issue? } \\
\text { 2. Is there a list or link to contact information for doctors, hospitals } \\
\text { and other allied health professionals? } \\
\text { 3. Can patients consult someone online on the site (e.g doctor or } \\
\text { nurse)? } \\
\text { 4. Does the site allow for the user to ask questions or state their } \\
\text { opinion? } \\
\text { 5. Are there various levels of information delivery (e.g. text, } \\
\text { graphics, sound, video, discussion boards, on-line chat forums, } \\
\text { patient tools, quiz, online health tests etc.)? } \\
\text { 6. Is the user required to input any information or select from drop } \\
\text { down menus other than for navigation? }\end{array}$ & 2 \\
\hline $\begin{array}{l}\text { Confidentiality } \\
\text { (only if personal } \\
\text { information is } \\
\text { collected) }\end{array}$ & 6 & $\begin{array}{l}\text { 1. Is there a statement about encryption or any security protection } \\
\text { used?* } \\
\text { 2. Does the site indicate the use of cookies or statistical } \\
\text { files/data?* } \\
\text { 3. Are the respective privacy laws that apply to the jurisdiction } \\
\text { stated?* } \\
\text { 4. Can a user logon just as a guest (eg. to use discussion boards or } \\
\text { join a chat session)?* } \\
\text { 5. Can a user edit their own information held by the site?* } \\
\text { 6. Does the site indicate the location of the site server plus any } \\
\text { mirror sites? } \\
\text { 7. Is there a privacy statement or disclosure policy visible for } \\
\text { information which is collected?* }\end{array}$ & 1 \\
\hline
\end{tabular}

$*=$ indicates optional operationalised sub-item depending on the site (ie. if personal information is collected, clinical information is provided)

\section{Final TOTAL Score (max. score out of 21)}

Calculation of total score is the summation of scores for each guideline = no. of applicable sub-items "ticked off as yes" divided by the total no. of applicable sub-items for that particular guideline multiplied by the weighted multiplier. 